\title{
Medical decision making among patients with heart failure - does migration background matter?
}

\author{
Olaf von dem Knesebeck ${ }^{1 *}$, Martin Scherer ${ }^{2}$, Gabriella Marx ${ }^{2}$ and Sarah Koens ${ }^{1}$
}

\begin{abstract}
Background: Some studies, mainly coming from the U.S., indicate disparities in heart failure (HF) treatment according to migration/ethnicity. However, respective results are inconsistent and cannot be transferred to other health care systems. Thus, we will address the following research question: Are there differences in the diagnosis and management of HF between patients with and without a Turkish migration background in Germany?

Methods: A factorial experimental design with video vignettes was applied. In the filmed simulated initial encounters, professional actors played patients, who consulted a primary care physician because of typical HF symptoms. While the dialog was identical in all videos, patients differed in terms of Turkish migration history (no/yes), sex (male/female), and age (55 years/75 years). After viewing the video, primary care physicians $(N=128)$ were asked standardized and open ended questions concerning their decisions on diagnosis and therapy.

Results: Analyses revealed no statistically significant differences $(p<0.05)$, but a consistent tendency: Primary care doctors more often asked lifestyle and psychosocial questions, they more often diagnosed HF, they gave more advice to rest and how to behave in case of deterioration, they more often auscultated the lung, and more often referred to a specialist when the patient has a Turkish migration history compared to a non-migrant patient. Differences in the medical decisions between the two groups ranged between 1.6 and $15.8 \%$. In 10 out of 12 comparisons, differences were below $10 \%$.

Conclusions: Our results indicate that are no significant inequalities in diagnosis and management of HF according to a Turkish migration background in Germany. Primary care physicians' behaviour and medical decision making do not seem to be influenced by the migration background of the patients. Future studies are needed to verify this result and to address inequalities in $\mathrm{HF}$ therapy in an advanced disease stage.
\end{abstract}

Keywords: Heart failure, Primary care, Medical decisions, Migration, Treatment, Disparities, Germany

\footnotetext{
* Correspondence: o.knesebeck@uke.de

${ }^{1}$ Institute of Medical Sociology, University Medical Center Hamburg-Eppendorf, Martinistr. 52, 20146 Hamburg, Germany

Full list of author information is available at the end of the article
}

C C The Author(s). 2020 Open Access This article is licensed under a Creative Commons Attribution 4.0 International License, which permits use, sharing, adaptation, distribution and reproduction in any medium or format, as long as you give appropriate credit to the original author(s) and the source, provide a link to the Creative Commons licence, and indicate if changes were made. The images or other third party material in this article are included in the article's Creative Commons. licence, unless indicated otherwise in a credit line to the material. If material is not included in the article's Creative Commons licence and your intended use is not permitted by statutory regulation or exceeds the permitted use, you will need to obtain permission directly from the copyright holder. To view a copy of this licence, visit http://creativecommons.org/licenses/by/4.0/ The Creative Commons Public Domain Dedication waiver (http://creativecommons.org/publicdomain/zero/1.0/) applies to the data made available in this article, unless otherwise stated in a credit line to the data. 


\section{Background}

There is extensive evidence of health care inequalities according to migration/ethnicity $[1,2]$. Such inequalities can be defined as differences in treatment provided to members of different ethnic groups not justified by the underlying health conditions or preferences about treatment of the patient [3]. Inequalities in health care according to ethnicity/migration were found for different conditions, including heart failure (HF) [4]. It is known that health care providers can contribute to such inequalities as they hold beliefs (stereotypes) about help seekers that can influence their interpersonal behaviour as well as their decision making $[1,5]$.

HF is a chronic condition with a major public health relevance. Worldwide, about 26 million people are affected [6], and in Europe and the United States HF is the leading cause of hospitalizations [7]. Despite improvements in therapy and treatment of relevant risk factors, the prognosis for patients with $\mathrm{HF}$ is still poor, with a 5 year mortality rate of $50 \%$ [8]. In terms of $\mathrm{HF}$ diagnosis, primary care physicians play an important role, because they often are the first contact point for patients affected [9]. Studies analysing racial or ethnic differences in outcomes among HF patients (e.g. hospitalizations, mortality) came to inconsistent results [4, 10-13]. The same holds true for studies analysing differences in treatment. While Bagchi et al. [4] found racial and ethnic disparities in the receipt of pharmacological therapy, a study of Thomas et al. [12] showed that the provision of guideline-based care was comparable for black, Hispanic, and white patients hospitalized with HF. Most of these studies on disparities in HF care according to ethnicity/migration were conducted in the U.S.. Less is known from Germany where the migration situation [14] as well as the health care system $[15,16]$ is different compared to the U.S.. In Germany, about $25 \%$ of the population (about 21 million people) have a migration background, i.e. they immigrated themselves or are the offspring of immigrant parents [17]. People with a Turkish background form the largest migrant group in Germany. Generally, people with migration background are members of the German statutory health insurance system and have the same entitlements to care as non-migrants. However, they often face cultural and language barriers to health care [14].

Against this background, we will address the following research question: Are there differences in the diagnosis and management of HF between patients with and without a Turkish migration background in Germany?

\section{Methods}

\section{Study design}

We applied a factorial experimental design using clinically authentic video vignettes $[18,19]$. The use of vignettes allow controlled manipulations while keeping other conditions like comorbidities and disease severity constant [20]. In the filmed simulated initial encounters, professional actors played patients, who consulted a primary care physician because of typical HF symptoms, including dyspnea, fatigue, peripheral edema, and cough [21]. These typical symptoms are highly suggestive for HF but not specific. Table 1 provides the information given in the vignette (for the complete script please see Additional file 1). We conducted workshops with clinical experts (cardiologists, general practitioners, and internists), HF patients, and members of the film production team, to develop the script for the videos. Reported symptoms were typical but not clear for HF, to achieve a clinically authentic scenario. The developed script was used for all vignettes, resulting in an identical dialogue in all video vignettes. In contrast, patients presented in the videos differed in terms of Turkish migration background (no/yes), sex (male/female), and age (55 years/75 years). Migration background was indicated by the name shown at the beginning of the video (Mr./Mrs. Yildiz (common Turkish name) vs. Mr./ Mrs. Schmidt (common German name)), by appearance, and by Turkish accent. Since in Germany only about 30\% of women with Turkish migration background wear a veil [22] we decided, to show Turkish women without a veil. Additionally, a veil would have led to a different appearance between men and women. Turkey was chosen as country of origin because people with a Turkish background are forming the largest migrant group in Germany [14]. Combination of the patient characteristics resulted in eight vignettes.

Table 1 Information given by the patient in the vignette

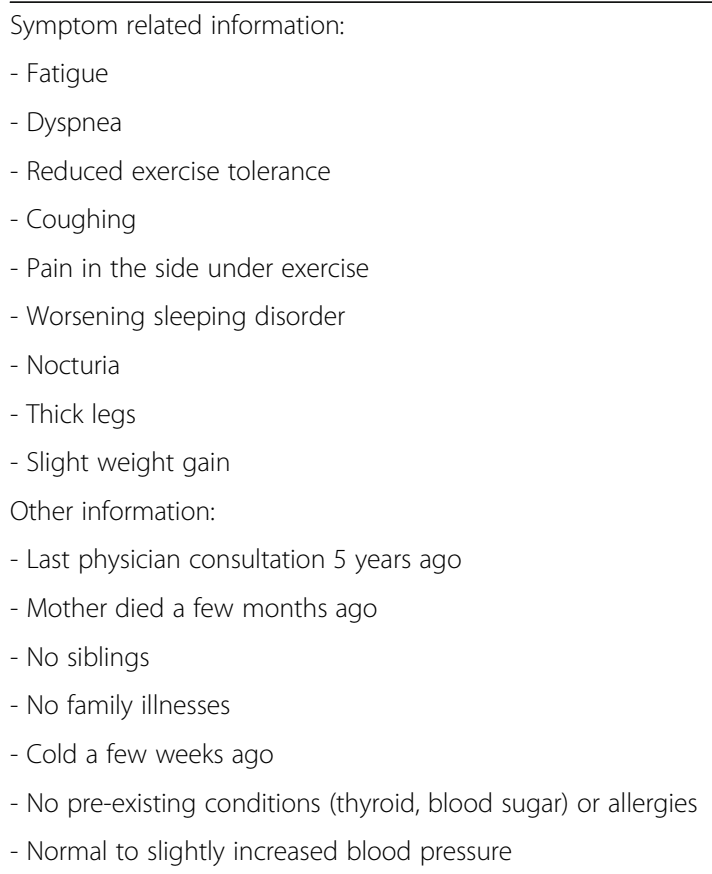


A casting was conducted to choose actors. Selected actors were instructed to portray a patient with HF symptoms in a similar way. For the purpose of an identical presentation, the first video was shown to the other actors. The part of the physician in the videos was spoken by a primary care doctor. To eliminate variation, one recording was used for all videos. A usual practice setting was chosen for the filming. The videos were shot from the perspective of the doctor who faced the patient. Thus, the patient was seen all the time. To ensure a realistic encounter, one cut videos were produced. The simulated encounter lasted about $7 \mathrm{~min}$, which reflects the average duration of a consultation with a primary care doctor in Germany [23]. In addition to the name, age of the patient was shown at the beginning of the videos. Primary care physicians viewed the video vignettes on a laptop in their own consulting room during or directly after their daily consultation hours. One video was shown to each doctor. The interviewers asked the participating doctors to view the patient in the video as a patient in their own practice.

\section{Participants}

Sample consisted of primary care doctors in Hamburg and adjacent regions of Lower Saxony and Schleswig Holstein. It was drawn from a comprehensive list of the Department of General Practice at the University Medical Center Hamburg-Eppendorf. General practitioners and internists with a maximum distance of $2 \mathrm{~h}$ driving time to the University Medical Center Hamburg-Eppendorf were invited to participate in a study on medical decision making in family practice per mail in a random order. To systematically investigate differences between physician attributes, the study population was stratified by a combination of physicians' sex and length of experience as board certified general practitioner or internist $(\leq 15$ years or $>15$ years) into four strata. To be included into the study, physicians had to work at least $20 \mathrm{~h}$ per week, mainly in primary care. To ascertain eligibility and willingness to participate, invited physicians were contacted by phone. Afterwards, we arranged an appointment for a 30 to $40 \mathrm{~min}$ individual in-person interview with the physicians in their own practice during or directly after their normal consultation hours. To acknowledge their participation and to partly offset lost revenue, participating physicians were provided a stipend.

According to a power calculation, a sample size of 128 physicians was needed to detect differences of $25 \%$ for the main effects (migration background of the patient) with a statistical power of $80 \%$ and a type-I error of 0.05 . For example, if $50 \%$ of physicians would diagnose $\mathrm{HF}$ in case of a patient with a migration background and 75\% of physicians would do so in case of a German patient, we would expect to detect a significant difference (at $\alpha=0.05) 80 \%$ of the time. Therefore, the final sample consisted of 64 female and 64 male primary care physicians; half of them with $\leq 15$ years of clinical experience and half of them with $>15$ years of clinical experience. Each of the eight vignettes was presented four times in each stratum. Within the strata, we allocated the vignettes randomly. Among eligible doctors, the participation rate was $50.4 \%$. According to a statement of the Ethics Committee of the Hamburg Medical Association (processing number: PV5663), no ethics approval was needed for the study. Written informed consent was obtained from each study participant.

\section{Measures}

After viewing the video, the physicians were asked standardized and open ended questions concerning their decisions on diagnosis and therapy. To assess physicians' information seeking behavior, the participants were asked if they would ask the person in the video any additional questions (yes/no) before deciding how to proceed and if so, what they wanted to ask (open ended). Additionally, they were asked about their tentative diagnosis (open ended) and what examinations and tests they would conduct (open ended). Moreover, we asked whether the physicians would prescribe medication (yes/no) and whether they would refer the patient to a specialist (yes/no). Finally, physicians were asked whether they would give lifestyle advice (yes/no) and if so, what they would advise (open ended).

\section{Analyses}

The following analyses focus on differences between patients with and without a Turkish migration background. For the open ended questions, coding frames were developed. In terms of the additional questions, answers were subsumed under three thematic categories: psychosocial aspects (e.g. family or job situation), lifestyle (e.g. smoking or physical activity), and medical history (e.g. previous illnesses or medication). Number of physicians were counted who mentioned HF as a possible diagnosis and who would auscultate the lung or the heart, and who would measure blood pressure. In terms of advice giving, answers were subsumed under three thematic categories: rest, risk behaviours (e.g. smoking or malnutrition), and behaviour in case of deterioration (e.g. follow-up visit or emergency department visit).

Absolute and relative frequencies by patient migration status were calculated in contingency tables. Because of the balanced factorial design, differences due to migration are unconfounded with the other design factors (patient sex and age and physician sex and length of medical experience). To examine variations in diagnostic and therapeutic decisions by migration, Chi2-tests were used. Statistical analyses were performed using the $\mathrm{R}$ statistical package [24]. $P$ values $<0.05$ are considered statistically significant. 


\section{Results}

Table 2 shows the diagnostic and therapeutic decisions of the primary care doctors according to the migration status of the patient with HF symptoms. About half of the physicians would ask additional questions about psychosocial aspects, while about $36 \%$ would ask questions about lifestyle and 29\% would address medical history. By trend, more physicians would ask questions about lifestyle and psychosocial aspects in case of a patient with a Turkish migration background, but the differences are not significant. About $81 \%$ of the physicians mention $\mathrm{HF}$ as possible diagnosis in case of a patient with a Turkish migration background, this rate is slightly lower in case of a German patient (not significant).

In terms of examinations, no significant differences according to migration status of the patient occur in auscultations of the lung and the heart as well as in the measurement of blood pressure. Portion of physicians who would prescribe medication is considerably low (about 3\%), with no significant differences according to migration. Slightly more physicians would give advice to rest and about behaviour in case of deterioration when the patient is a migrant from Turkey, but again differences are not significant. About one third of the physicians would refer the patient to a specialist. This rate is $15.8 \%$ higher when the patient has a migrant background (not significant).

\section{Discussion}

In this study, we analysed differences in the diagnosis and management of HF between patients with a Turkish migrant background and non-migrant patients in
Germany using a factorial experimental design with video vignettes. Results revealed no significant differences, but a consistent tendency: Primary care doctors more often asked lifestyle and psychosocial questions, they more often diagnosed HF, they gave more advice to rest and how to behave in case of deterioration, they more often auscultated the lung, and more often referred to a specialist when the patient is a migrant. Differences in the medical decisions between the two groups ranged between 1.6 and $15.8 \%$. In 10 out of 12 comparisons, differences were below $10 \%$. Thus, overall, there were no significant disparities in the diagnosis and management of HF between patients with and without a migration background in our study.

While this is the first study analysing disparities in HF care according to ethnicity/migration in Germany, there are some studies coming from other countries, especially from the U.S.. These studies, which are often based on retrospective analyses of medical record data, came to inconsistent results with regard to medications and guideline-based care $[4,10,12]$. In contrast, the present study surveys primary care physicians' behaviour and medical decision making regarding various diagnostic and therapeutic aspects. This approach rests on the assumption that health care providers hold beliefs (stereotypes) about help seekers that can influence their behaviour as well as their decision making [1, 5, 25, 26]. In this regard, some studies found inequalities in doctor's questioning and advice giving according to the ethnic background of the patient [27], while others did not find respective disparities [28, 29]. However, none of these studies addressed HF and none came from

Table 2 General practitioner's decisions in case of a patient with heart failure symptoms: differences according to migration background

\begin{tabular}{|c|c|c|c|c|}
\hline & Total $(\mathrm{N}=128)$ & $\begin{array}{l}\text { Patient with migration } \\
\text { background }(n=64)\end{array}$ & $\begin{array}{l}\text { Patient without migration } \\
\text { background }(n=64)\end{array}$ & $\mathrm{p}^{*}$ \\
\hline \multicolumn{5}{|l|}{ Additional questions } \\
\hline Lifestyle & $46(35.9 \%)$ & $26(40.6 \%)$ & $20(31.3 \%)$ & 0.27 \\
\hline Psychosocial aspects & $63(49.2 \%)$ & $32(50.0 \%)$ & $31(48.4 \%)$ & 1.00 \\
\hline Medical history & $37(28.9 \%)$ & $21(32.8 \%)$ & $16(25.0 \%)$ & 0.33 \\
\hline Diagnosis heart failure & $99(77.3 \%)$ & $52(81.3 \%)$ & $47(73.4 \%)$ & 0.39 \\
\hline \multicolumn{5}{|l|}{ Examinations } \\
\hline Auscultation of the lung & $117(91.4 \%)$ & $61(95.3 \%)$ & $56(87.5 \%)$ & 0.21 \\
\hline Auscultation of the heart & $114(89.1 \%)$ & $59(92.2 \%)$ & $55(85.9 \%)$ & 0.40 \\
\hline Measurement of blood pressure & $105(82.0 \%)$ & $54(84.4 \%)$ & $51(79.7 \%)$ & 0.65 \\
\hline Prescription of drugs & $4(3.1 \%)$ & $3(4.7 \%)$ & $1(1.6 \%)$ & 0.62 \\
\hline \multicolumn{5}{|l|}{ Advice } \\
\hline Rest & $28(21.9 \%)$ & $17(26.6 \%)$ & $11(17.2 \%)$ & 0.28 \\
\hline Risk behaviours & $15(11.7 \%)$ & $7(10.9 \%)$ & $8(12.5 \%)$ & 1.00 \\
\hline Behaviour in case of deterioration & $25(19.5 \%)$ & $16(25.0 \%)$ & $9(14.1 \%)$ & 0.18 \\
\hline Referral & 44 (34.4\%) & 27 (42.4\%) & 17 (26.6\%) & 0.09 \\
\hline
\end{tabular}

* significances ( $p$-values) of $\mathrm{Chi}^{2}$-Test 
Germany. In this regard, it is important to highlight that results on treatment disparities according to migration cannot be generalized as respective studies have a specific frame of reference. They were conducted in a country with a specific health care system. There are studies indicating variations in diagnostic and therapeutic decisions between different health care systems. For example, in the U.S., more physicians would ask questions about lifestyle, order tests, and prescribe medication than in Germany when they see a patient with symptoms of a coronary heart disease [30]. Additionally, the former studies on treatment disparities according to migration focus on specific treatments, for a specific condition, and analyse specific ethnic or migrant groups. This also holds true for the findings presented here; they refer to primary care treatment decisions among HF patients with and without Turkish migrant background in Germany.

In Germany, about 25\% of the population (about 21 million people) have a migration background, i.e. they immigrated themselves or are the offspring of immigrant parents [17]. This group is very heterogeneous with regard to country of origin, cultural background, and language. People with a Turkish background form the largest migrant group in Germany (about 3 million people [31]). In our study, Turkish migration background was indicated by the name shown at the beginning of the video (Mr./Mrs. Yildiz (Turkish) vs. Mr./ Mrs. Schmidt (German)), by appearance, and by Turkish accent, while the dialogue was the same as in the videos with non-migrant patients. Thus, results of our study refer to those persons with a Turkish migration background who do not face language barriers. According to estimations, this applies to about two thirds of all people with a Turkish migration background in Germany [32]. Transferability of our results to other migrant groups is limited, because the level of integration might vary between migrant groups and it cannot be excluded that this may influence physicians' medical decisions.

There are more methodological aspects that need to be considered when interpreting our findings. To meet the challenges associated with research on medical decision making, we applied a factorial design with video vignettes [18-20, 33]. The balanced factorial designs allows the estimation of unconfounded and independent differences by migration background. This is a strength of the factorial design compared to other study designs, because in other studies on medical decision making it is often difficult to control for other factors, which may also influence physicians' decisions [33].

In terms of limitations, firstly, generalizability of our findings is limited to Hamburg and adjacent regions. Secondly, the study population is not representative for primary care physicians, as physicians were selected according to sex and length of clinical experience, to represent the stratification criteria in the factorial design. Additionally, the videos showed a first encounter between doctor and patient with HF symptoms. Therefore, it has to be considered that some physicians may have initiated some diagnostic and therapeutic steps in a subsequent consultation. A limitation of the use of filmed simulated encounters is that physicians may have answered differently in the interview compared to real patients. Nevertheless, a study on validity of clinical vignettes to examine quality of care indicates that vignettes are a valid method to assess physicians' practice vignettes [34] and are generalizable to real patients [33]. To address the issue of external validity and to ensure the clinical authenticity of the vignettes, a number of steps were taken. Clinical experts (primary care physicians and cardiologists) as well as HF patients were involved in developing the script for the vignettes. Additionally, we employed a professional film team to produce the vignettes and chose professional actors to play the HF patients. The videos were filmed in a normal practice setting. Moreover, to foster that study participants identified themselves with the depicted situation, the encounters were filmed from the perspective of the doctor. The participants viewed the vignettes in their own consultation rooms. Furthermore, the vignettes were presented to the physicians during or directly after their practice hours, thus it is likely that they encountered real patients right before the interviews. Additionally, the physicians were asked to view the person in the video as a patient in their own practice. To prevent biased answers towards social acceptance, the participants were told that the interview was not a test but we were interested in medical decision making of primary care physicians. After they viewed the video, the physicians were asked how typical the patient in the video was for a patient in their own practice. The patient was considered very typical or rather typical by $83.6 \%$ of the respondents. Additionally they were asked how realistic the dialogue in the vignette was for an encounter in their own practice. Of the doctors, $84.4 \%$ said the dialogue was very realistic or rather realistic.

\section{Conclusion}

Our results indicate that there are no significant inequalities in diagnosis and management of HF according to a Turkish migration background in Germany. Primary care physicians' behaviour and medical decision making do not seem to be influenced by the migration background of the patients. Although this is a desirable result, it has to be verified in future studies. Moreover, as we focused on an initial encounter of a patient with HF symptoms, further research should address inequalities in HF therapy in an advanced disease stage. 


\section{Supplementary information}

Supplementary information accompanies this paper at https://doi.org/10. 1186/s12875-020-01260-4.

Additional file 1. Complete script of the vignettes.

\section{Abbreviations}

HF: Heart Failure; US: United States

\section{Acknowledgements}

We would like to thank all participating primary care physicians.

\section{Authors' contributions}

OK initiated the analyses, drafted the manuscript and interpreted the findings. SK was involved in conducting the study, performed the analyses, and gave feedback on drafts. MS contributed to writing and also provided feedback on drafts. GM was involved in preparing the study, collecting data, and gave feedback on drafts. All authors read and approved the final manuscript.

\section{Funding}

This paper is part of the research project "Disparities in the diagnosis and treatment of women and men with heart failure" funded by the Federal Ministry of Education and Research (FKZ 01GL1711). The funders had no role in study design, data collection and analysis, decision to publish, or preparation of the manuscript. Open Access funding enabled and organized by Projekt DEAL.

\section{Availability of data and materials}

The datasets used and/or analysed during the current study are available from the corresponding author on reasonable request.

\section{Ethics approval and consent to participate}

Informed consent was signed by all participating physicians. According to a statement of the Ethics Committee of the Hamburg Medical Association (processing number: PV5663) no ethics approval was needed for the study.

\section{Consent for publication}

Not applicable.

\section{Competing interests}

The authors declare that they have no competing interests.

\section{Author details}

${ }^{1}$ Institute of Medical Sociology, University Medical Center Hamburg-Eppendorf, Martinistr. 52, 20146 Hamburg, Germany. ²Department of General Practice and Primary Care, University Medical Center Hamburg-Eppendorf, Martinistr. 52, 20146 Hamburg, Germany.

Received: 29 May 2020 Accepted: 2 September 2020

Published online: 13 September 2020

\section{References}

1. van Ryn M, Fu SS. Paved with good intentions: do public health and human service providers contribute to racial/ethnic disparities in health? Am J Public Health. 2003;93:248-55.

2. Lutfey Spencer K, Grace M. Social foundations of health care inequality and treatment bias. Annu Rev Sociol. 2016;42:101-20.

3. Institute of Medicine. Unequal treatment: confronting ethnic and racial disparities in health care. Washington: national Academic Press; 2002.

4. Bagchi AD, Stewart K, McLaughlin C, Higgins P, Croghan T. Treatment and outcomes for congestive heart failure by race/ethnicity in TRICARE. Med Care. 2011;49:489-95.

5. Balsa Al, McGuire TG, Meredith LS. Testing for statistical discrimination in health care. Health Serv Res. 2005;40:227-52.

6. Ponikowski P, Anker SD, AlHabib KF, Cowie MR, Force TL, Hu S, et al. Heart failure: preventing disease and death worldwide. ESC Hear Fail. 2014;1:4-25.

7. Ambrosy AP, Fonarow GC, Butler J, Chioncel O, Greene SJ, Vaduganathan M, et al. The Global Health and economic burden of hospitalizations for heart failure lessons learned from hospitalized heart failure registries. J Am Coll Cardiol. 2014:63:1123-33.

8. Benjamin EJ, Virani SS, Callaway CW, Chamberlain AM, Chang AR, Cheng S, et al. American Heart Association Council on epidemiology and prevention statistics committee and stroke statistics subcommittee, heart disease and stroke Statistics-2018 update a report from the American Heart Association. Circulation. 2018;137:E67-E492.

9. Stork S, Handrock R, Jacob J, Walker J, Calado F, Lahoz R, et al. Treatment of chronic heart failure in Germany: a retrospective database study. Clin Res Cardiol. 2017;106:923-32.

10. Rathore SS, Foody JM, Wang Y, Smith GL, Herrin J, Masoudi FA, et al. Race, quality of care, and outcomes of elderly patients hospitalized with heart failure. JAMA. 2003:289:2517-24.

11. Brown DW, Haldeman GA, Croft JB, Giles WH, Mensah GA. Racial or ethnic differences in hospitalization for heart failure among elderly adults: Medicare, 1990 to 2000. Am Heart J. 2005;150:448-54.

12. Thomas KL, Hernandez AF, Dai D, Heidenreich P, Fonarow GC, Petersen ED, et al. Association of race/ethnicity with clinical risk factors, quality of care, and acute outcomes in patients hospitalized with heart failure. Am Heart J. 2011;161:746-54.

13. Downing NS, Wang C, Gupta A. Association of racial and socioeconomic disparities with outcomes among patients hospitalized with acute myocardial infarction, heart failure, and pneumonia. JAMA Netw Open. 2018;1:e182044

14. Razum O, Bozorgmehr K. Restricted entitlements and acces to health care for refugees and immigrants: the example of Germany. Glob Soc Policy. 2016;16:321-4.

15. Busse R, Blümel M, Knieps F, Bärninghausen T. Statutory health insurance in Germany: a health system shaped by 135 years of solidarity, selfgovernance, and competition. Lancet. 2017;390:882-97.

16. Ridic G, Gleason S, Ridic O. Comparisons of health care systems in the United States, Germany and Canada. Mater Sociomed. 2012;24: 112-20.

17. Federal Agency for Civic Education. Bevölkerung mit Migrationshintergrund I. [Population with migration background I.] https://www.bpb.de/ nachschlagen/zahlen-und-fakten/soziale-situation-in-deutschland/61646/ migrationshintergrund-i. Accessed 12 May 2020.

18. Bönte M, Knesebeck Ovd, Siegrist J, Marceau L, Link C, Arber S et al. Women and men with coronary heart disease in three countries: are they treated differently?, Womens Health Issues. 2008;18:191-8.

19. Knesebeck Ovd, Gerstenberger E, Link C, Marceau L, Roland M, Campbell S. et al. Differences in the diagnosis and management of 17 type 2 diabetes in 3 countries (US, UK, and Germany): results from a factorial experiment. Med Care. 2010;48:321-6.

20. Hillen MA, van Vliet LM, de Haes HC, Smets EM. Developing and administering scripted video vignettes for experimental research of patient-provider communication. Patient Educ Couns. 2013;91:295-309. https://doi.org/10.1016/j.pec.2013.01.020

21. Ponikowski P, Voors AA, Anker SD, Bueno H, Cleland JGF, Coats AJS, et al. ESC guidelines for the diagnosis and treatment of acute and chronic heart failure. Eur Heart J. 2016:37:2129-200.

22. Schührer S. Persons of Turkish origin in Germany. Findings from the representative study "selected migrant groups in Germany 2015" (RAM) working paper 81 of the research Center of the Federal Office. Nürnberg: Federal Office for Migration and Refugees; 2018.

23. Irving G, Neves AL, Dambha-Miller H, Oishi A, Tagashira H, Verho A, et al. International variations in primary care physician consultation time: a systematic review of 67 countries. BMJ Open. 2017;7:e017902

24. R Core Team, R: a language and environment for statistical computing, R foundation for statistical computing, $R$ foundation for statistical computing, Vienna, http://www.r-project.org. Accessed 3 Dec 2019.

25. Van Ryn M, Burgess D, Malat J, Griffin J. Physicians' perception of patiens' social and behavioural characteristics and race disparities in treatment recommendations for men with coronary artery disease. Am J Public Health. 2006;96:351-7.

26. Cooper LA, Roter DL, Carson KA, Beach MC, Sabin JA, Grennwald AG, et al. The associations of clinicians' implicit attitude about race with medical visit communication and patient ratings of interpersonal care. Am J Public Health. 2012;102:979-87.

27. Van Ryn M. Avoiding unintended bias: strategies for providing more equitable health care. Minn Med. 2016;99:40-6. 
28. Arber S, McKinlay JB, Adams A, Marceau L, Link C, O'Donnell A. Influence of patient characteristics on doctors' questioning and lifestyle advice for coronary heart disease: a UKJUS video experiment. Br J Gen Pract. 2004;54: 673-8.

29. McKinlay JB, Link C, Freund KM, Marceau L, O'Donnell A, Lutfey K. Sources of variation in physician adherence with clinical guidelines: results from a factorial experiment. J Gen Intern Med. 2007;22:289-96.

30. von dem Knesebeck O, Bönte M, Siegrist J, Marceau L, Link C, Arber S, et al. Country differences in the diagnosis and management of coronary heart disease - a comparison between the US, the UK and Germany. BMC Health Serv Res. 2008;8:198.

31. Federal Institute for Population Research. [Population with migration background (2005-2018)] Wiesbaden, 2018, https:/www.bib.bund.de/ Permalink.html?id=13782578. Accessed 12 May 2020.

32. Social Indicators Information Service. Zuwanderer mit türkischem Migrationshintergrund schlechter integriert. [Immigrants with a Turkish migration background less integrated.] https://www.gesis.org/fileadmin/upload/forschung/ publikationen/zeitschriften/isi/isi-46.pdf. Accessed 12 May 2020.

33. Evans SC, Roberts MC, Keeley JW, Blossom JB, Amaro CM, Garcia AM, et al. Vignette methodologies for studying clinicians' decision-making: validity, utility, and application in ICD-11 field studies. Int J Clin Health Psychol. 2015; 15:160-70.

34. Peabody JW, Luck J, Glassman P, Dresselhaus TR, Lee M. Comparison of vignettes, standardized patients, and chart abstraction: a prospective validation study of 3 methods for measuring quality. JAMA. 2000;283:1715-22.

\section{Publisher's Note}

Springer Nature remains neutral with regard to jurisdictional claims in published maps and institutional affiliations.

Ready to submit your research? Choose BMC and benefit from:

- fast, convenient online submission

- thorough peer review by experienced researchers in your field

- rapid publication on acceptance

- support for research data, including large and complex data types

- gold Open Access which fosters wider collaboration and increased citations

- maximum visibility for your research: over $100 \mathrm{M}$ website views per year

At BMC, research is always in progress.

Learn more biomedcentral.com/submissions 